\title{
Budget Constraints as Link between Sports Economics and E-Sports? An Analysis of the Development of Hamburg's Total Attendance at Professional Sports and Potential Lessons Learned for E-Sports
}

\author{
By Till Wewer*
}

\begin{abstract}
The aim of this research is to initiate a knowledge transfer from sports economics to upcoming e-sports research. Sports economics has shown, especially for the USA, that there is an overall budget constraint for leisure time activities and thus for spending not only on sports events. Therefore, an increase in stadium capacities will possibly lead to a shift from other activities, i. e. cinemas and restaurant, but not to an increase in overall spending and employment. This research tries to show this shift effect for the attendance volume at professional sports' events in Hamburg. Hamburg is an interesting case because within the reviewed decade three professional teams have vanished, two new were established and football stadium capacities were increased. The results show that especially the increase of St. Pauli's stadium capacities but as well the establishing of the basketball team Towers probably had a significant (in) direct influence on attendance at HSV Handball crowd. Furthermore, after the first teams of HSV Handball and Hamburg Freezers Ice Hockey were withdrawn from professional sports competition a massive increase in attendance to their amateur alternatives occurred. The effects on HSV football and the American football team "Huskies" would need further research. The results indicate that upcoming e-sports will have an effect on the established leisure activities, probably including traditional professional sports. Thus, further research is required to analyse the effect of upcoming e-sports upon traditional sports, but as well cinemas, restaurants and concerts, before considering subsidies for e-sports.
\end{abstract}

Keywords: e-sports, Hamburg Sports, Public Subsidies, Sports Economics, Total Attendance

\section{Introduction: Linking Sports Economics and E-Sports}

E-sports is a comparably new phenomenon but at the same time well recognized in the world of professional sports. It might become the next big thing in sports entertainment. E-sports might be a part of its future or even the future of professional sports entertainment. Thus, the idea of this contribution is to link - in line with the history of the International Hamburg Congress on Sports, Economy and Media - Sports Economics and E-sport research. Furthermore, the piece also

${ }^{*}$ M.A. (Public Economics, Law \& Politics), Consultant (Public Sector), C/O Nordlicht Management Consultants, Germany. 
seeks to initiate a knowledge transfer due to various similarities not only from an economic perspective.

For sixteen years, the International Hamburg Congress on Sports, Economy and Media has discussed different perspectives on, chances, possibilities but as well disadvantages of mega sports events. From the start, practitioners, scholars and officials discussed chances and effects of Hamburg's application for Olympia 2012. In 2015, the discussion focused on the city's application to host the games in 2024. In addition, in 2016 the question why it was rejected in a referendum was analysed with the findings showing that the public were sensitive about costs and possible negative effects, i.e. on rents (Wewer 2017, 110ff.) as the supporters had expected. The Congress 2017 moved on to the potential future of sports: E-sports. Since E-sports are a comparably new phenomenon, the idea of this contribution is to initiate a knowledge transfer from 16 years of congress history as a starting impulse for E-sports research.

Professional sports and E-sports share many similarities. Sports Economics focusses mainly on the effects of professional sports on the (local) economy. Thus, on those events that attracts many visitors, sponsors and public subsidies. For example, in case of increasing stadium capacities and its effects or mega sports events like the Olympia or the FIFA World-Cup. E-Sports is already attracting many visitors in parts of Asia (Schneider/Yin 2016), its number of fans is increasing in most western countries and might even become Olympic. Furthermore, e-sports are based on a competition similar to popular sports. However, even if someone might argue, that e-sport is no sports there is a strong link between all, not only sports events: They compete for leisure time and money. Sports Economics has shown, especially for the USA, that the budget for leisure time and spending is limited. Thus, that an in- or decrease in capacities will rather lead to a shift from one activity to another than to increase in total demand.

This analysis will briefly review the key findings and argumentation from sports economics. Afterwards, the development of the Total Attendance to professional sports teams in Hamburg between 2006 and 2016 will be analysed by descriptive statistics to outline this effect for this German case. Finally, questions for upcoming e-sports will be derived from those findings to start a knowledge transfer from sports economics and to initiate the scientific discussion about esports.

\section{Public Subsidies to Professional Sports - Literature Review from Public Economics}

If professional sport is discussed in public economics, it usually is all about public subsidies for building or increasing stadium capacities in favour of professional sports teams. One of the reasons is the sheer amount. In the USA and between 1994 and 2006 over $60 \%$ of the costs of building professional sports stadiums were public financed resulting in one billion dollars per years average of public subsidies (Rappaport and Wilkinson 2001, Fort 2006, Tresch 2016: 1) 
For simplification, the basic assumption of public economics that a subsidy can only be economically justified if a market failure is proven. However, it is more than doubtful that professional sports or e-sports will ever be able to prove this market failure (cf. Tresch 2016). Thus, public subsidies are in most cases not economically justifiable and only a gift to the sports club or owner from a rational, economic perspective.

Unfortunately, in public it is generally assumed that the construction of the stadium and the running of the (enlarged) stadium will create additional jobs, increase aggregate spending in entertainment and the per capita income level (cf. Tresch 2016: 4). Tierney (2005) called this deep-rooted believe and overestimation of a full stadium a "circus Maximus syndrome". The assumption is that for increasing capacity (local) construction workers will be hired (labour game). In addition, that this will increase local spending because they spend their wages for rent, food or leisure time activities. Secondly, due to increased capacities, more people buy tickets and spend money on food and beverages (direct spending). The suppliers will order more food and drinks but as well more employees to be able to fulfil the increased demand around the match (indirect spending). Moreover, the additionally hired employee receives an income that he or she will spend in advance in the local economy (induced spending). This common public argumentation concentrates on the impact of the increased capacities (cf. Tresch 2016).

However, an impact analysis is an inadequate measure to justify subsidies or measure the overall effects on a local economy by a stadium construction. The adequate measure would be a cost-benefit-analysis that does not focus only on the construction but as well on what would have happened without it.

At first, any public investment in construction, in a school, street or office, would have had the same effect on the local economy (Tresch 2016, Coates and Humphrey 2000). Thus, the simple impact of building a stadium does not justify subsides. Actually, this could even have negative effects on the economy, because infrastructure or university cannot be built at the same time as the arena is under construction due to limitations in workforce or money. Furthermore, it will most certainly not create many additional jobs. This could only occur, if construction workers were unemployed otherwise. However, this is not true nowadays. In the $21^{\text {st }}$ century, skilled workers would be hired for other construction jobs instead. Thus, increasing stadium capacities does not lead to more wages for construction specialist that could possibly be spent. In conclusion, it would be rather surprising if public subsidies to construct sport arenas are able to have a possible effect on the local employment rate. Schwester (2007: 93) and Miller (2002) concluded for construction jobs "in short (...) the effect was zero."

Secondary, the running of the increased or constructed stadium will not simply increase local spending, but only generate a shift. Commonly it is assumed that a new arena will lead to additional spending for tickets and beverages and this to more ordered supply and suppliers. If we attend a baseball match, we will not watch a movie in the theatre, attend a baseball match or visit an opera (cf. Leeds 2005: 402, Tresch 2016, Coates and Humphrey 2000). The time limitation is obvious. Furthermore, our budget is limited as well. Of course, it might happen 
that we will spend more than planned in our leisure time, but most people will limit their budget in the next days or weeks. Thus, the additional spending for professional sports will lead to decreased spending in other sectors.

Hamilton and Kane (1997) concluded even a loss in the state-wide economy due to the construction of Baltimore Oriole Park. Coates and Humphrey (2000, 2003) concluded an overall negative, "harmful effect" on earnings due to stadium construction for 36 metropolitan areas over the time of 27 analysed years. "Spending as a function of sports merely displaces other spending" (Baade and Sanderson 1997, cf. Schwester 2007: 93). Sport spending does not have an overall, but only a "substitution" effect (Rosentraub 1997, Baade 1996).

The effect of a professional sports arena is different from the impact. The reason is the overall budget constraint due to time and money limitations. The reasons why this effect was shown for even more cases in the US is that it is simpler to show this effect for US sports, because in most US sports it is possible to transfer teams from town to town almost form one day to another and occurs comparably often. Or those lockouts occurred in a few cases. Lockouts are less likely in German professional sports as well as the transfer of teams to different cities, although this has happened in other sports as football due to different traditions and less big sports and therefore less possibly transferred teams. Thus, it is possible to compare spending almost without a lack in time by comparing the day before the teams has transferred or locked out with the day after. In these cases interference of other effects on spending behaviour, i.e. in the long run, are less effective.

For the US, the shift effect cannot be denied. Thus, this analysis takes a closer look, if it can as well be found for the case of Hamburg.

\section{The Hamburg Case: Development of Hamburg's Total Attendance in Professional Sport}

In the following, it will be examined, if this shift in attendance can as well be seen in the city of Hamburg's Total Attendance to various professional sports between 2006 and 2016. Based on the findings from US sports it shall be possible to find the same shift effect in Hamburg due to three effects within this decade. An increase in stadium capacities in football. Three teams going out of business in Handball, Ice Hockey and Volleyball. In addition, the starting of two completely new teams in Football and Basketball. Thus, the research question, in this case, shall be: Can an interconnected Budget Constraint be derived from the Total Attendance to Professional Sports Teams in Hamburg between 2006 and 2016 ?

\section{Research Design: Descriptive Statistics of Total Attendance}

For this purpose the Total Attendance of eight professional teams from six sports from Hamburg from 2007 to 2017 is compared by descriptive statistics. The Total Attendance per season, thus, from summer to summer, is compared based on the average attendance times regular league matches. Friendly matches, relegation 
(HSV football) and Cup-matches are excluded for all teams, since it is very difficult to get this data ex-ante for all the teams especially in minor interested sports.

\section{Overview: Increased Capacity and Decreased Number of Teams?}

This research aims to compare the last ten year total attendance to Hamburg's professional sports with a special focus upon the shift in recent year due to the drop out of business of one handball and one hockey team in 2015. Additionally, in the last years a new basketball and American football team were established in Hamburg and St. Pauli, the second biggest football team, increased its stadium capacity until 2015.

The biggest football (US: soccer) team in Hamburg in terms of attendance is the Hamburger Sport Verein (HSV). The team USP was the only remaining founding member of German Bundesliga (1. Division) until 2018. The team did very well until 2010 including international semi-finals (Haider 2013, 461; 469). Nevertheless, ever since, the performance of the team got worse and worse, climaxing in avoiding second league only by winning relegation matches twice. Moreover, it lost its USP final in 2018. The biggest sports stadium in Hamburg is theirs. It is the Volksparkstadion with a capacity of 57,000 (cf. NDR 2017). In 2009 , the club announced plans to increase the capacity to 61,000 visitors (cf. Kicker 2009), but the plan was stopped due to financial and manpower limitations (cf. Abendblatt 2009), but probably as well due to a decreasing average and probably due to decreasing success.

The second biggest sports team in Hamburg in terms of attendance is St. Pauli. This football team of 2. Bundesliga, besides the season 2010/2011 for one year in Bundesliga, is worldwide known for the skull in front of two bones as their symbol. In addition, for rather homogenous, left supporters and for its active fight against commercialism and xenophobia (cf. The Guardian 2015). The stadium Millerntor's capacities were increased step-by-step from 19,800 in 2009 to 29,546 in 2015 (cf. Stadium Guide 2018). Since the increase in capacity was based on expectations of additional visitors, we well have a special look on the situation at Millerntor and possibly interconnected demand in other sports.

The Hamburg Freezers were an Ice Hockey team in the first German division located in Hamburg from 2002-2016 (cf. Der Tagesspiegel 2016). In 2014 they made it to the semi-final of the German championship (ibid.). After the season 2015-2016 the team was taken out of business officially due to the increasing budget deficit (ibid.). For the aim of this research the Crocodiles, the second best Ice Hockey team in Hamburg, are taken into account as well. This team is an amateur team in the third German division North (cf. crocodiles-eishockey.de).

The HSV Handball played in the same indoor arena as the Freezers, which are located opposite of the HSV football stadium. The team was transferred from the city of Lübeck to Hamburg in 2002 and was only a cooperation with the classic HSV (cf. Abendblatt 2018). The team has won the German championship in 2011 and the European Champions League in 2013 (cf. Abendblatt 2016a). The cooperation with HSV was ended after the professional team was taken out of 
business following the season 2015/2016 due to the permanent deficit (ibid.). The name had to be changed to Handball Sport Verein Hamburg instead of Hamburger Sport Verein Handball and the logo and the initials of the more traditional football club are not allowed to be used anymore (ibid.). To observe if this had led to a shift we will take the former second, amateur team into account as well.

Since 2014/2015 Hamburg has furthermore a second division basketball team, the Hamburg Towers (cf. Die Zeit 2014), and since 2015/2016 the Hamburg Huskies re-established first division American football in Hamburg (cf. www.gohuskies.de). We will have a special focus upon the development in Total Attendance in those teams that have been taken out of business and as well those that have been newly established.

There are many factors, which influence the total attendance to a professional sports event, i.e. economic, sociodemographic, quality and insecurity (cf. Heinemann 1995, cited from Radtke 2017: 266). For the purpose of this research, those will be left aside. They are only taken into broader account for discussing the results per season.

\section{Research, Questions \& Results: Attendance Seems to Have Shifted}

In the last years, St. Pauli increased its capacity, two teams dropped out of business and two new sports appeared on the Hamburg's sports supply map. This setting should give us the chance to observe a shift that indicates an interconnected demand within total attendance in professional sports in Hamburg. From a scientific perspective the Null-hypothesis - the assumption of an interconnected demand, which shall be rejected - would be that this research will show no indications for the shift of attendance from one professional sport team to another.

Table 1. Results: Total Attendance in Hamburg's Professional Sports 2006-2016 (per thousand)

\begin{tabular}{|l|c|c|c|c|c|c|c|c|c|c|c|}
\hline & $2006 /$ & $2007 /$ & $2008 /$ & $2009 /$ & $2010 /$ & $2011 /$ & $2012 /$ & $2013 /$ & $2014 /$ & $2015 /$ & $2016 /$ \\
2016 & 2017 \\
\hline $\begin{array}{l}\text { HS } \\
\text { V }\end{array}$ & 949.7 & 941.3 & 933.0 & 939.1 & 925.6 & 908.4 & 899.6 & 880.1 & 905.3 & 912.9 & 889.8 \\
\hline $\begin{array}{l}\text { St.P } \\
\text { auli }\end{array}$ & 302.1 & 314.7 & 379.8 & 358.4 & 414.0 & 394.7 & 411.4 & 482.3 & 416.8 & 498.7 & 499.8 \\
\hline $\begin{array}{l}\text { Free } \\
\text { zes }\end{array}$ & 265.8 & 223.7 & 201.3 & 181.8 & 183.0 & 239.3 & 203.6 & 227.5 & 233.7 & 234.6 & $\mathrm{X}$ \\
\hline $\begin{array}{l}\text { HS } \\
\text { V } \\
\begin{array}{l}\text { Hnd } \\
\text { b }\end{array}\end{array}$ & 136.3 & 147.8 & 167.1 & 176.7 & 181.7 & 176.5 & 147.1 & 150.4 & 113.8 & 108.1 & 54.9 \\
\hline $\begin{array}{l}\text { Tow } \\
\text { rs }\end{array}$ & $\mathrm{X}$ & $\mathrm{X}$ & $\mathrm{X}$ & $\mathrm{X}$ & $\mathrm{X}$ & $\mathrm{X}$ & $\mathrm{X}$ & $\mathrm{X}$ & 42.6 & 43 & 45.7 \\
\hline $\begin{array}{l}\text { Cro- } \\
\text { codi } \\
\text { les }\end{array}$ & $\mathrm{X}$ & 2.3 & 2.6 & 2.6 & 1.7 & 1.7 & 3.7 & 5 & 6.5 & 6.7 & 45 \\
\hline $\begin{array}{l}\text { Hus } \\
\text { kies }\end{array}$ & $\mathrm{X}$ & $\mathrm{X}$ & $\mathrm{X}$ & $\mathrm{X}$ & $\mathrm{X}$ & $\mathrm{X}$ & $\mathrm{X}$ & $\mathrm{X}$ & $\mathrm{X}$ & 1 & 1 \\
\hline
\end{tabular}

Source: transfermarkt.de (HSV; St. Pauli), eishockeypedia.de (Freezers); dkb-handballbundesliga.de (HSV Handball), Abendblatt 2017 (Towers), eishockey-online.com (Crocodiles), Radtke 2017, 265 (Huskies 2015/2016, estimated for 2016/2017). 
Thus, this situation indicates four questions:

1. Does Hamburg's total attendance from season $2006 / 2007$ to $2016 / 2017$ indicate a shift of demand as an indicator for an interconnected demand?

2. Did the attendance at HSV Handball and Freezers decrease after St. Pauli stadium capacity was increased? Alternatively, after Towers and Huskies appeared?

3. Which teams seemed to have profited from the defunct of the first division Handball and Ice Hockey teams?

4. Where all supports of those teams "taken over" by other teams or is there professional sports potential left fallow?

\section{HSV Handball: Decrease due to St. Pauli \& Towers? Shift to $3^{\text {rd }}$ Division!}

For the development in total attendance at HSV Handball we can observe two major steps of decrease. The first in season 2012/2013 at the same time when St. Pauli increased its capacity and sold over 400,000 tickets (cf. dkb-handballbundesliga.de/ transfermarkt.de). The total attendance decreased from around 180,000 to 150,000 per season. And this happened although HSV Handball won the European Champions League at the same season and St. Pauli's one year in Bundesliga had been two years ago (cf. transfermarkt.de). Thus, this shift cannot be explained by the success of one of the teams, HSV Handball was not able to reach the former level of support later again. The second significant decrease down too little above 100,000 occurred in the season 2014/2015. The same season that the new basketball team "Towers" appeared (cf. Die Zeit 2014). This team is doing ok, but not great and is still in the second division. Again, this cannot be explained by the success, but rather by an alternative, more interesting leisure time offer.

The last massive increase occurred when in 2016/2017 the professional team was taken out of business. The former second team became the first team in $3^{\text {rd }}$ division north, which immediately led to a few attendance records in the third handball division (Abendblatt 2018). It is most likely to assume a shift here since not only a few officials, smaller sponsors, but as well older players decided to remain with the club. However, the average of attendance dropped from around 6,500 to 3,500 . The team moved from the modern arena with a capacity of 13,296 to the municipal Sporthalle Hamburg with a maximum 4,144 visitors. Thus, this could partially be explained by a smaller arena, but not completely. Another shift seems to have occurred.

St. Pauli matches are sold out almost any time. Economic theory implies furthermore that an increase in its stadium capacity should have an influence on other leisure activities. The results of this analysis indicate that this might have led to a decrease in attendance for Hamburg Handball. A theoretic explanation for this could be, that HSV Handball was attended by many people who did want to attend sports, but either for coolness, financial or other reasons decided to choose something else than the biggest team HSV (football). As soon as it was possible, at 
least a certain part decided to leave Handball in advance of the MillerntorStadium. Similar, the emergence of Towers basketball in Hamburg gave the chance to move on to the new and cool other sport, which could have led another part of the audience to shift. Furthermore, the increase in third division in Handball after the professional teams dropped out indicates, that there is still a remaining core of fans, who wants to see handball independent of the league.

\section{Freezer: Shift to Crocodiles}

It seems like a similar shift occurred in Hamburg's Ice Hockey after the Freezers dropped out of business in the same year. When the Freezers vanished, the number of season passes sold at Crocodiles increased from 17 in 2015/2016 to over 1,000 in 2016/2017 (Abendblatt 2016b). The average attendance increased from 467 to 1,783 (eishockey-online.com). Furthermore, similar a prominent player and a few smaller sponsors moved on (cf. Die Zeit 2016), which underlines the assumption that many fans that wanted to support ice hockey in their city have shifted from $1^{\text {st }}$ to $3^{\text {rd }}$ division.

\section{Huskies \& HSV (Football): Further Research Necessary}

Until now, it seems that American football Huskies (cf. Radtke 2017: 265) was not able to profit from the vanishing of Freezers and $1^{\text {st }}$ league handball. The HSV football shows a decreasing tendency (cf. transfermarkt.de) at the same time as St. Pauli increased its capacity. However, as mentioned before in the same years the HSV returned to play its cliché style of football: Horrible and worse. Thus, to derive an indication from this further research would be necessary.

\section{Concluded Result: Interconnected Demand/Shift of Audience Heavily Indicated}

This leads to the following results to the four raised questions (cf. section 3.3):

1. This analysis heavily indicates an interconnected demand for professional sports within Hamburg's professional teams within the last ten years. Thus, the null hypothesis is rejected. A shift most certainly occurred.

2. The Total Attendance of HSV Handball seems to have been influenced by the increase of St. Pauli's stadium capacity as well as the appearance of the Tower basketball team. The appearance of the Huskies, the football team, does not seem to have been influential.

3. It is most likely that the third division amateur teams in handball and ice hockey mainly profited from the disappearance of the first league teams in the same sport.

4. However, until now not all "fans" seemed to have been taken over. HSV (football) and Huskies seemed not to have profited and as well the named 
amateur clubs show a significantly lower average. Further research would be needed to find out whether bars, cinemas, restaurants or other amateur sports (volleyball) or teams (Altona $93,4^{\text {th }}$ division football ) have profited or if this indicates a potential for e-sports, robo-cup or dron-wars.

\section{Lessons Learned For E-Sports: Who will be disadvantaged by the Shift of Audience?}

The findings of this analysis strongly indicated the demand for Professional Sports is interconnected for the case of Hamburg 2006 to 2016. This is another argument for the economic theory of budget constraints due to limitations in time and money for a case outside of the USA. Thus, the basis of further discussion shall be that additional supply in leisure time activities will not lead to additional demand, but only to a shift.

This means for upcoming e-sports that it needs to be discussed not only from a scientific perspective in which relation e-sports are to already established entertainment, like professional sports, theatres or restaurants. This contribution aims to initiate the knowledge transfer of findings from sports economics for the esport discussion. Moreover, to keep in mind, that economically it is not only important who gains but as well who loses.

For the start of the discussion of economic effects, more precise the economic impact, of e-sports the following questions should be taken into account for further research:

If interest in e-sports will increase

- Does this lead to a shift away from established professional sports, i.e. from Formula One or Formula E (cf. Robeers in this edition), from Bundesliga to E-Bundesliga or from Olympia to E-Olympia?

- Does the shift of attendance mainly occur from other, less popular sport or lower leagues or amateur sports?

- Are other leisure time activities like cinemas, theatres or concerts? In addition, will this disadvantage small theatres (Abaton) and local shopping, since larger companies (Cinemaxx) are able to react faster due to large capacities and participate in the shift by offering e-sports shows?

- What is the effect on restaurants and wages, if e-sports are becoming more and more popular?

- What will be the effects on classic television and media?

\section{Conclusion: Discuss Negative Effects as Well to Successfully Promote Large Events}

These questions shall be taken into account if advantages and disadvantages of upcoming e-sports are discussed. In theory, these shall even be answered before it is discussed if e-sports receive public subsidies or support. The Olympic 
Referendum in Hamburg 2015 and International Hamburg Congress on Sports, Economy and Media 2016 have shown that the public is much more aware of the disadvantage and those who lose as most officials were able to imagine. The findings of this contribution to the Congress 2017 indicate that the shift in demand exists not only in the USA but as well for a European setting like the case of Hamburg. A successful, additional leisure time offer, like e-sports, will lead to a decreased interest in other fields, possibly in professional sports, theatres or restaurants. The reasons are traceable to the limitations in time and money. Simplified, we cannot attend or factually watch two events at the same time. The reason is an economic budget constraint. This constraint needs to be kept in mind for the starting discussion of upcoming e-sports. An honest discussion about chances of not only e-sports cannot leave aside these negative effects if it takes place in 21 st century.

\section{References}

Baade R (1996) Professional Sports as Catalyst for Metropolitan Economic Development. Journal of Urban Affairs, 1-17.

Baade R, Sanderson A (1997) The Employment Effect of Teams and Sports Facilities. In Noll R, Zimbalist A (eds) Sports, Jobs and Taxes: The Economic Impact of Sports Teams and Stadiums.

Coates D, Humphreys B (2000) The Stadium Gambit and local Economic Development, Regulation, 15-20.

Coates D, Humphreys B (2003) The Effect of Professional Sports on Earnings and Employment in the Service and Retail Sector in U. S. cities, Regional Sciences and Urban Economics, 175-198.

Fort R (2006) Sport Economics, $2^{\text {nd }}$ Edition. Upper Saddle River, NJ: Prentice Hall.

Haider L (Ed) 2013. HSV - Ein Verein, eine Stadt, immer dabei [HSV - A club, a city, always with you].

Hamilton B, Kahn P (1997) Baltimores's Camden Yards Ballpark. In Noll R, Zimbalist A (eds) Sports, obs and taxes: The Economic Impact of Sports teams and Stadiums.

Miller PA (2002) The Economic Impact of Sport Stadium Construction: The case of the Construction Industry in St. Louis MO. Journal of Urban Affairs, 159-173.

Leeds M (2005) Sieger und Verlierer im Spiel der Stadien. Die ökonomische Bedeutung von Sportstätten in den USA[Winners and losers in the game of stadiums. The economic importance of sports facilities in the USA]. In. Marschik M, Müllner R, Spitaler G, Zinganel M (eds) Das Stadion. Geschichte. Architektur. Politik. Ökonomie.

Radtke T (2017) Potenzielle Erfolgsfaktoren bei der Vermarktung der German Fottball League am Beispiel der Hamburger Huskies [Potential success factors in the marketing of the German Football League on the example of the Hamburg Huskies]. In Förster J, Hebbel-Seeger A, Horky T, Schulke HJ (eds) Sport und Stadtentwicklung, 260-291.

Rappaport J, Wilkerson C (2001) What are the Benefits of Hosting a Major League Sport Franchise? Economic Review 2001. Kansas City Federal Reserve Bank.

Rosentraub M (1997) Major League Losers: The Real Cost of Sports and Who's Paying for It. New York: Basic Books.

Schneider F, Yin DY (1996) The dynamics of digital play in Asia. Asiascape: Digital Asia 2016(3): 1-2, 5-15. 
Schwester RW (2007) An Examination of the Public Good Externalities of Professional Athletic Venues: Justification for Public Financing? Public Budgeting \& Finance, 89-109.

Tresch RW (2016) Example 20.3 Justifying Public Subsidies to Professional Sports Teams with Econmic Impact Analysis. Retrieved from https://bit.ly/2Q5qsdB.

Tierney J (2005) The Circus Maximus Syndrome, The New York Times, June $11^{\text {th }}$.

Wewer T (2017) Nimby \& (N)Olympia - An Analysis of the Olympic Referendum in Hamburg 2015. In Förster J, Hebbel-Seeger, Andreas H, Thomas SHJ (eds) Sport und Stadtentwicklung, 110-131.

\section{Newspaper Articles Online Sources}

Abendblatt (2009) HSV verschiebt Stadionausbau mangels Geld und Personal. Retrieved from https://bit.ly/2BfidDt. [Accessed 21 October 2018, cited as Abendblatt 2009].

Abendblatt (2016a) Der Aufstieg und der Fall der HSV-Handballer. Retrieved from https://bit.ly/2A43YQ9. [Accessed 21 October 2018, cited as Abendblatt 2016).

Abendblatt (2016b) Crocodiles starten in neue Ära. Retrieved from https://bit.ly/2Fw Phvb. [Accessed 28 October 2018].

Abendblatt (2017) Wer sind die Zuschauer der Hamburg Towers? Retrieved from https:// bit.ly/2BgaBka. [Accessed 28 October 2018].

Abendblatt (2018) Handball Sport Verein Hamburg: Aufgerichtet aus den Ruinen Retrieved from https://bit.ly/2BgxfJb. [Accessed 21 October 2018].

Der Tagesspiegel (2016) Hamburg Freezers - Ende eines Abenteuers? Retrieved from https://bit.ly/2Bgu18P. [Accessed 21 October 2018].

Die Zeit (2014) Ball her. Retrieved from https://bit.ly/2Fs2u8w. [Accessed 21 October 2018].

Die Zeit (2016) Die Krokodile greifen an. https://bit.ly/2A3FXca. [Accessed 28 October 2018].

Kicker (2009) HSV baut Stadion aus. Retrieved from https://bit.ly/2QSLWaJ. [Accessed 21 October 2018].

NDR (2017) Volksparkstadion: Geliebt wird nur der Name. Retrieved from https://bit. ly/2Q6X8U6. [ Accessed 21.10.2018]

The Guardian (2015) St Pauli: the club that stands for all the right things ... except winning https://bit.ly/2Fs91Qf. [Accessed 21 October 2018].

The Stadiumguide. Millerntor-Stadion (2018) Retrieved from https://bit.ly/2Kfjrlb. [Accessed 21 October 2018].

\section{Sources for Total Attendance in Hamburg's Professional Sports 2006-2016}

transfermarkt.de (HSV; St. Pauli), eishockeypedia.de (Freezers); dkb-handballbundesliga.de (HSV Handball), Abendblatt (2017) (Towers), eishockey-online.com (Crocodiles), Radtke 2017, 265 (Huskies 2015/2016, estimated for 2016/2017). Please note that Total Attendance to amateur but as well professional sports is in Germany not included into statistics for example from the central bureau of statistics. Thus, additional online sources had to be taken into account. 
